\title{
En la periferia de un texto judeoárabe Yefet b. 'Eli contra filósofos y astrólogos, entre tafsīr y realidad
figurada (precedido de unas notas filológicas)
}

Juan Pedro Monferrer Sala Universidad de Córdoba*

El presente trabajo consta de dos partes diferenciadas al tiempo que complementarias. En la primera parte ofrecemos un análisis filológico de la traducción de Da 1:20 realizada por Yefet b. 'Eli en comparación con la versión de Sa'adyah y la traducción árabe cristiana más antigua con que contamos (Sin. ar. 1). En tanto que en la segunda parte nos ocupamos del análisis de su comentario, centrado en un aspecto periférico de este (no en el corazón de la exégesis bíblica en sí), tratando de mostrar cómo el autor caraíta lleva a cabo una crítica de la intelectualidad oficial del momento. Para ello, sirviéndose de la escena que narra el texto daniélico, el autor recurre a figurar la escena de un mağlis en el que el debate presidido por el monarca es mantenido por la intelectualidad oficial, es decir los pensadores rabbanitas que son calificados como 'filósofos y astrólogos' -que él interpreta como 'sabios del rey'-, y la no oficial, los caraítas, que representan el saber superior y la verdad que emana de la Ley revelada por Dios. Los primeros figuran a los sabios de Nabucodonosor del texto de Daniel y los segundos a los jóvenes judíos, que aventajan en saber y perfección a aquéllos.

Palabras Clave: Yefet b. 'Eli; Sa'adyah; caraítas; rabbanitas; tafsīr; filósofos; astrólogos; mağlis; judeoárabe.

In the Periphery of a Judaeo-Arabic Text: Yefet b. 'Eli against Philosophers and Astrologers, between Tafsír and Figurative Reality (Preceded by some Philological Notes).- The present article has two complementary parts. In the first part we offer a philological analysis of Yefet b. 'Eli's translation of Daniel 1:20 in comparison with Sa'adyah's version and the oldest Christian Arabic translation (Sin. ar. 1) which has survived. In the second part, we analyse Yefet b. 'Eli's commentary focusing on its periphery (not in the heart of the Biblical exegesis in itself) thereby showing how the Karaite author carried out an attack against the official intelligentsia of those days. For this, the author makes use of the scene narrated in the Danielic text to represent the scene of a mağlis in which the debate is chaired by the monarch. This debate is held, with the king's wise men, the official intelligentsia, i.e. the Rabbanite thinkers, on the one hand and, on the

\footnotetext{
f1mosaj@uco.es
} 
other hand, the non-offical thinkers, the Karaites, who represent the superior knowledge and the truth which emanates from the Law revealed by God. The Rabbanites represent Nebuchadnezzar's wise men of Daniel's text, and the Karaites are Daniel and the young Jews, who are superior to them in science and perfection.

Keywords: Yefet b. 'Eli; Sa'adyah; Karaites; Rabbanites; Tafsīr; Philosophers; Astrologers; Mağlis; Judaeo-Arabic.

Abū 'Alī Hasan b. 'Alī al-Lawī al-Bașrī, más conocido como Yefet b. 'Eli ${ }^{1}$, fue sin duda el más reputado exegeta entre los caraítas de Palestina $^{2}$. Con su militancia literalista en la interpretación del texto sagrado, rehuyendo el peso de la tradición, no sólo se erigió en cabeza visible de aquellos que se opusieron al gran $\mathrm{Sa}$ 'adyah Gaon durante la segunda mitad del siglo $\mathrm{X}^{3}$, sino que además sus obras son la llave que nos permite conocer como era el clima intelectual de aquellos días, al tiempo que nos posibilita poder trazar una historia cultural de la intelectualidad caraíta de la Jerusalén del momento ${ }^{4}$. A todo lo cual cabe sumar la recepción de la exégesis de los caraítas palestinenses en territorios que estaban fuera de dār al-islām y por ende, no arabófonos ${ }^{5}$.

${ }^{1}$ H. Ben-ShammaI, «Japheth Ben Eli ha-Levi», Encyclopedia Judaica (2. ${ }^{\text {a }}$ ed. New York: Thomson Gale 2007), vol. XI, págs. 86-87; S. L. Skoss, «Jafet b. Ali ha-Levi», Encyclopedia Judaica (Berlin: Verlag Eschkol 1928-34), vol. VIII, págs. 754-759. Cf. M. G. WeChSLER, «Yefet's life and works», en IDEM, The Arabic Translation and Commentary of Yefet Ben 'Eli the Karaite on the Book of Esther. Edition, Translation, and Introduction (Leiden: Brill 2008), págs. 3-11.

${ }^{2}$ H. MüLLER, Religionwissenschaftliche Minoritättenforschung. Zur religionhistorischen Dynamik der Karäer im Osten Europas (Wiesbaden: Harrassowitz 2010), págs. 46-49.

${ }^{3}$ S. Poznański, «The Karaite Literary Opponents of Saadiah Gaon in the Tenth Century», The Jewish Quarterly Review (en lo sucesivo, JQR) [OS] 18 (1906), págs. 209250: 228-238 ( $\left.\mathrm{n}^{\circ} 12\right)$ [cf. S. PoznaŃski, The Karaite Literary Opponents of Saadiah Gaon (London: Luzac \& Co. 1908), págs. 20-30, nº 12]. Además, Ph. BiRnBaum, «Yefet b. Ali and his influence on Biblical Exegesis», JQR 32 (1941), págs. 51-70: 64-67.

${ }^{4}$ D. Frank, «The Shoshanim of Tenth-Century Jerusalem: Karaite Exegesis, Prayer, and Communal Identity», en The Jews of Medieval Islam: Community, Society, \& Identity, ed. D. Frank (Leiden - New York - Köln: Brill, 1995), págs. 199-246: 204.

${ }^{5} \mathrm{Ph}$. Birnbaum, «Yefet b. 'Ali and His Influence on Biblical Exegesis (Continued)», JQR 32 (1941), págs. 159-174: 170. 
De la importancia de sus escritos, y concretamente de sus comentarios a textos bíblicos ${ }^{6}$, género en el que fue el campeón entre los autores caraítas de aquellos días ${ }^{7}$, nos da cuenta no sólo la tradición generada por las obras del autor ${ }^{8}$, sino también las colecciones privadas orientales de las que proceden los manuscritos de sus obras, como los contenidos en la colección Firkovich ${ }^{9}$, los adquiridos por Adler en Egipto y Turquía a finales del siglo XIX ${ }^{10}$, así como los materiales hallados en la Geniza de El Cairo ${ }^{11}$, cuya información ha enriquecido ingentemente el conocimiento acerca de las relaciones entre rabbanitas y caraítas durante la Edad Me$\operatorname{dia}^{12}$.

Si bien una de las áreas más favorecidas por las investigaciones dedicadas a los textos de autores judíos elaborados en judeoárabe es la de los

\begin{abstract}
${ }^{6}$ Véase al respecto M. Polliack, The Karaite Tradition of Arabic Bible Translation. A Linguistic \& Exegetical Study of Karaite Translations of the Pentateuch from the Tenth \& Eleventh Centuries CE (Leiden - New York - Köln: E. J. Brill, 1997), págs. 37-45. Acerca del orden de los libros seguido en sus comentarios, de acuerdo con el codex utilizado por la comunidad caraíta jerosolimitana del siglo X, véase E. L. Marwick, «The Order of the Books in Yefet's Bible Codex», JQR 33 (1943), págs. 445-460. Véase, además, H. Ben-Shammai, S. Stroumsa et al. (eds), Judaeo-Arabic Manuscripts in the Firkovitch Collections. Yefet ben 'Eli al-Basri. Commentary on Genesis: A Sample Catalogue (heb.)
\end{abstract} (Jerusalem: Ben Zvi Institute, 2000).

${ }^{7}$ M. STEINSChNeIDER, Die arabische Literatur der Juden: ein Beitrag zur Literaturgeschichte der Araber, grossentheils aus handschriftlichen Quellen (Frankfurt am Main: J. Kauffmann 1902), págs. 81-84. Acerca de la repercusión de su labor exegética, dentro y fuera del caraísmo, Birnbaum, «Yefet b. Ali and his influence on Biblical Exegesis (Continued)», 170-174, e IDEM, «Yefet b. Ali and his influence on Biblical Exegesis (Continued)», JQR 32 (1942), págs. 257-271.

${ }^{8}$ G. TAMANI, «La tradizione delle Opere di Yefet b. Ali», Bulletin d'Études Karaites 1 (1983), págs. 27-76.

${ }^{9}$ Los manuscritos de Yefet b. 'Eli ya suscitaron la atención del Prof. Haggai BeNShammar en su The Doctrines of Religious Thought of Abū Yūsuf Ya'qūb al-Qirqisānī and Yefet Ben 'Elī (Jerusalem: The Hebrew University,1977, Ph. D. Dissertation), cuyo vol. II es una selección de textos, y que no nos ha sido posible consultar.

${ }^{10}$ E. N. AdLER, «Karaitica», JQR [OS] 12 (1900), págs. 674-687: 677 (n ${ }^{\text {os } 214, ~ 219) . ~}$

${ }^{11}$ C. F. BAKER, «Judaeo-Arabic Material in the Cambridge Genizah Collection», Bulletin of the School of Oriental and African Studies 58 (1995), págs. 445-454: 448.

${ }^{12}$ S. D. GolteIn, A Mediterranean Society. The Jewish Communities of the world as Portrayed in the Documents of the Cairo Geniza (Berkeley - Los Angeles: University of California Press 1967-1988), vol. II, págs. 7-8 y 520 (n. 5). 
comentarios bíblicos, en cambio, sigue habiendo obras que aguardan un estudio en detalle y sistemático de este tipo de obras, ya sobre aspectos concretos, ya con carácter general, por el interés que estos presentan en varios aspectos: por un lado, en el de la propia exégesis, aunque también el aspecto lingüístico, y, además, en el que podríamos denominar como periférico o contextual, es decir todos aquellos ámbitos que, de un modo u otro, se hallan relacionados con el Sitz im Leben del autor de la obra.

De acuerdo con lo anterior, en el presente artículo nos ocupamos de dos aspectos distintos en sí, aunque al tiempo conectados. El primero recoge un análisis filológico de la traducción de Da 1:20 de Yefet b. 'Eli, que comparamos con la de $\mathrm{Sa}$ 'adyah y la traducción árabe cristiana más antigua con que contamos en la actualidad (Sin. ar. 1), recurriendo también al texto hebreo (en lo sucesivo, TH) y a la Pešittā como referentes textuales respectivos. El segundo, a su vez, presenta el análisis del comentario de Yefet b. 'Eli, buscando con ello evidenciar la crítica que realiza el autor a los rabbanitas como casta intelectual oficial de la época, pues así creemos que se desprende de la labor exegética realizada por Yefet b. ' Eli $^{13}$ en el fragmento que ha dado lugar al presente estudio, incluido en la traducción-comentario al Libro de Daniel ${ }^{14}$, tal vez el último que realizara el autor caraíta ${ }^{15}$.

YefeT B. 'Eli y Su TRAdUCCión DE DANIEL 1:20, EN COMPARACión CON OTRAS DOS VERSIONES

La versión árabe del texto bíblico que ofrece Yefet b. 'Eli presenta una serie de aspectos dignos de tener en consideración a la luz de otras traducciones, realizadas tanto por judíos como por cristianos. De estos segundos tomaremos como modelo la versión más antigua de una traducción árabe con la que contamos en la actualidad, la versión contenida en el ms. sinaíti-

${ }^{13}$ D. Frank, «Karaite Exegesis», en Hebrew Bible, Old Testament. The History of Its Interpretation. I. From the beginnings to the Middle Ages (until 1300), ed. Magne SÆвø (Göttingen: Vandenhoeck \& Ruprecht, 2000), págs. 110-128: 119-120. In extenso, por ejemplo, en su comentario a Oseas, en The Arabic Commentary of Yefet Ben 'Ali the Karaite on the Book of Hosea, ed. Ph. BiRnBaum (Philadelphia: Dropsie College, 1942).

${ }^{14}$ Jephet ibn Ali the Karaite, A Commentary on the Book of Daniel, edited and translated by D. S. Margoliouth (Oxford: Clarendon Press, 1889).

${ }^{15}$ PoznAŃski, The Karaite Literary Opponents of Saadiah Gaon, p. 20, n. 3. 
co árabe 1, del siglo IX d.C., en tanto que de los primeros hemos recurrido al célebre Tafsìr de Sa'adyah, de cuya versión (de escaso interés a nivel exegético para el presente trabajo) ${ }^{16}$ ofrecemos inmediatamente debajo en un cuadro sinóptico junto con la versión de Yefet b. 'Eli con el objeto de llevar a cabo el análisis del texto que presenta el autor caraíta ${ }^{17}$.

\section{Versión de Sa'adyah ${ }^{18}$}

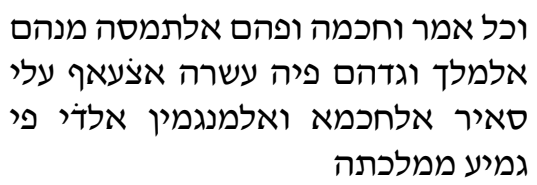

«Y en todo asunto de sabiduría y entendimiento que les preguntó el rey los halló diez veces superiores a todos los hombres de sabiduría y astrología que había en todo su reino».

\section{Versión de Yefet b. 'Eli}



«Y [acerca de] todas las cuestiones de sabiduría y entendimiento sobre las que les consultó el rey, los halló diez veces superiores a todos los filósofos y los magos que había en todo su reino».

Las dos versiones judeoárabes que acabamos de transcribir nos informan de que las estrategias adoptadas por ambos traductores ante el texto de Daniel son muy similares ${ }^{19}$. Como podemos observar, ambos han man-

${ }^{16}$ J. Alobaidi, The Book of Daniel. The Commentary of R. Saadia Gaon. Edition and translation (Bern: Peter Lang, 2006), págs. 85 (texto judeoárabe) y 431 (trad.).

${ }^{17}$ Sobre las traducciones judeoárabes de autores caraítas, véase M. Polliack, The Karaite tradition of Arabic Bible translation: a Linguistic and Exegetical Study of Karaite Traditions of the Pentateuch from the Tenth and Eleventh century (Leiden - New York - Köln: Brill 1997). Véanse, además, de la misma autora, «Medieval Karaite Views on Translating the Hebrew Bible into Arabic», Journal of Jewish Studies 47 (1996), págs. 64-84, y «Medieval Karaite Methods of Translating Biblical Narrative into Arabic», Vetus Testamentum 48 (1998), págs. 375-398.

${ }^{18}$ Alobaidi, The Book of Daniel, 84 (texto judeoárabe), 430 (trad.).

${ }^{19}$ Adviértase lo que se dice a propósito de ambos autores en H. Ben-ShammaI, «The Judeo-Arabic vocabulary of Saadya's Bible translations as a vehicle for eschatological messages: The case of Saadya's usages of the $8^{\text {th }}$ form of Arabic QDR», en Esoteric and Exoteric Aspects in Judeo-Arabic Culture, eds. B. Hary \& H. Ben-Shammal (Leiden Boston: Brill 2006), págs. 191-225 y 201 (n. 34). 
tenido la estructura sintagmática que presenta el $\mathrm{THM}^{20}$, que consiste en una oración principal de la que dependen dos proposiciones, una adjetiva y otra adverbial, dependiendo de esta segunda otra proposición adjetiva. En el siguiente esquema queda representado el mapa sintagmático del versículo:

$\leftarrow$ (Propadj1) proposición adjetiva 1

(OP) Oración principal

$\leftarrow$ (Propadv) proposición adverbial

$\leftarrow$ (Propadj2) proposición adjetiva 2

De este modo, las correspondencias sintagmáticas entre los tres textos quedan de la forma siguiente:

\begin{tabular}{|c|c|c|c|}
\hline & Yefet b. 'Eli & Sa'adyah & THM \\
\hline Padv & وكل خطاب حكمة فهم & וכל אמר וחכמה & בְּינָּל דְּבר חָכְמַת \\
\hline Padj2 & الذى طلب منهم الملك & אלמלך אלתה מנהם & 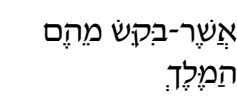 \\
\hline OP & كل الفلاسفة عشرة اضعاف على & אלעצה עלי עיה עשרה & 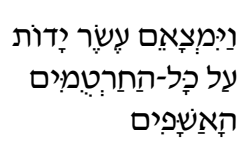 \\
\hline Padj1 & الذين فى كل ملكه & אמלדי פי גמיע & אִשֶר בְּכָל-מַלְכוּתוֹ \\
\hline
\end{tabular}

Como se advierte, las correspondencias son totales entre el texto hebreo masorético (en lo sucesivo, THM) y las dos versiones judeoárabes, con la peculiaridad que ofrece Sa'adyah en PAdj2 (אלתמסה מנהם אלמלך = iltamasa-hu min-hum al-malik) en la que falta el pronombre relativo

\footnotetext{
${ }^{20}$ Sobre la técnica aplicada a sus traducciones de textos bíblicos por Yefet b. 'Eli, véase Birnbaum, «Yefet b. 'Ali and His Influence on the Bible Exegesis (Continued)», págs. 165-166.
} 
allad $\bar{\imath}$, tal vez debido al lapsus calami de un copista por contaminatio con אלת (<allat[i]).

A su vez, en cuanto a las correspondencias léxicas que se dan entre THM y las dos traducciones, como puede deducirse del cuadro sinóptico que ofrecemos debajo, se advierten la serie de estrategias que señalamos inmediatamente después del cuadro de correspondencias:

\begin{tabular}{|c|c|c|}
\hline Sa'adyah & Yefet b. 'Eli & THM \\
\hline וכל & وكل & וְכל \\
\hline אמר & & דְּבַר \\
\hline וחכמה & حكمة & דְמַה \\
\hline ופהם & فهم & ינָה \\
\hline - & 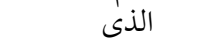 & אר \\
\hline אלתמסה & طلب & בִּקִּשׁ \\
\hline מנהם & منهم & אתֶֶָם \\
\hline אלמלך & الملك & הַפְּלֶּף \\
\hline וגדהם & وجدهم & 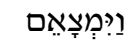 \\
\hline פיה & - & \\
\hline עשרה & عشرة & גר \\
\hline אצעאף & اضعاف & דָדוֹת \\
\hline עלי & على & \\
\hline - & كل & \\
\hline סאיר אלחכמא & الفلاسفة & חַרְטַפְִּים \\
\hline ואלמנגמין & والسحرة & הַשִֵָׁפים \\
\hline אלדי & الذين & \\
\hline פי גמיע & في كل & \\
\hline ממלכתה & ملكه & כוּתו \\
\hline
\end{tabular}

De interés traductológico son los cinco términos que comparamos a continuación a partir del original hebreo del que parten las dos traducciones judeoárabes:

- THM děbar ('discurso; palabra; cosa') es traducido por Sa'adyah como amr ('cosa; asunto'), frente a Yefet b. 'Eli que interpreta hițāb ('discurso; charla; escrito'), siguiendo Sa'adyah, de este modo, más de cerca el texto de THM.

- THM biq·qěš ('pedir; demandar, requerir'), de la forma piel, ha 
sido vertido por Sa'adyah como iltamasa ('buscar; solicitar'), en tanto que Yefet b. 'Eli prefiere talaba ('pedir; buscar').

- THM ha-ḥarẹtum.mîm ('los adivinos; astrólogos; magos'), que Sa'adyah traduce en $s \bar{a}$ 'ir al-ḥukamā' ('el resto de los sabios'), en tanto que Yefet b. 'Eli vierte al-falāsifah ('los filósofos').

- THM hä-'ašš šafim ('los prestidigitadores; magos; nigromantes') es traducido en el Tafsìr de Sa'adyah por al-munağğimūn ('los astrólogos') y Yefet b. 'Eli opta por al-saḥarah ('los magos; brujos; hechiceros').

- THM malék k̂t ('reino') es traducido por Sa'adyah como mamlakah ('reino'), mientras que Yefet b. 'Eli ha preferido la opción mulk ('soberanía; poder real realeza; monarquía').

Además, Yefet b. 'Eli y Sa'adyah optan por estrategias léxicas idénticas cuando THM permite recurrir a una forma árabe cognada ${ }^{21}$. Hay que señalar que, como se sabe, el árabe mulk (en Yefet b. 'Eli) no es un cognado morfológico del hebreo malěk k̂t , aunque sí lo son los siguientes términos:

$\begin{array}{lll}\text { Kōl } & \leftrightarrow & \text { Kull } \\ \text { ḥōknmā } & \leftrightarrow & \text { hikmah } \\ \text { melek } & \leftrightarrow & \text { malik } \\ \text { 'éser } & \leftrightarrow & \text { 'ašrah } \\ \text { cal } & \leftrightarrow & \text { 'alà }\end{array}$

Un aspecto más a tener en consideración en la traducción de Da 1:20 es la de la posible relación (personalmente creemos que indirecta, y sólo en algunos casos muy concretos) con las antiguas versiones realizadas por los traductores árabes cristianos a partir de Vorlagen, en este caso concreto griegas o siríacas. Tal podría ser el caso del texto contenido en el ya mencionado manuscrito sinaítico árabe 1 (s. IX), cuyo cotejo con las

${ }^{21}$ Sobre el uso de formas cognadas hebreas-árabes, véase A. Maman, Comparative Semitic Philology in the Middle Ages: from Sa'addiah Gaon to Ibn Barūn (10 th $-12^{\text {th }} \mathrm{c}$.), transl. into English D. Lyons (Leiden - Boston: Brill 2004), págs. 165-166. 
dos versiones judeoárabes ofrece las siguientes consideraciones a partir del cuadro sinóptico que damos:

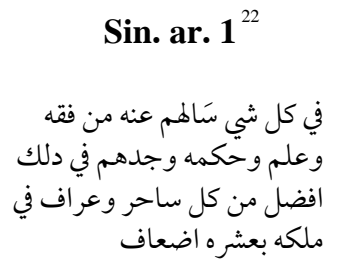

\author{
Sa'adyah \\ וכל אמר וחכמה ופהם

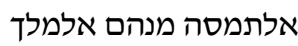 \\ וגדהם פיה עשרה אצעאפ מלת אליף \\ עלי סאיר אלחכמא \\ ואלמנגמין אלדי פי גמיע אלחיע \\ ממלכתה ואלמניו
}

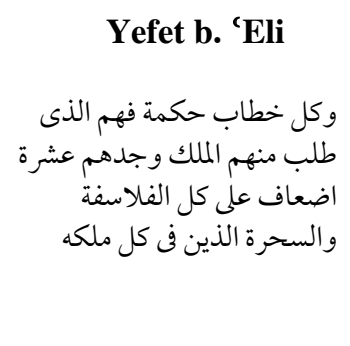

Yefet b. ' Eli

Lo primero que salta a la vista es que la disposición sintagmática no es la misma en Sin. ar. 1, pues mientras que Yefet b. 'Eli y Sa'adyah siguen el orden de palabras marcado por THM, en cambio Sin. ar. 1 sigue un esquema sintáctico distinto: en el que mantiene la OP de la que hace depender la Propadv, aunque ha prescindido de las dos PropAdj, con lo que tenemos la siguiente estructura:

(OP) Oración principal $\leftarrow(\mathrm{Padv})$ proposición adverbial

De este modo, las correspondencias sintagmáticas resultantes al comparar las dos versiones judeoárabes con la traducción árabe cristiana quedan de este modo:

Sin. ar. 1

Padv

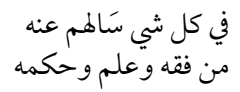

$\operatorname{Padj} 2$

$\mathrm{OP}$

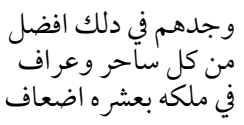

Padj1

\section{Sa'adyah}

וכל אמר וחכמה ופהם

وكل خطاب حكمة فهم

אלתמסה מנהם אלמלך

וגדהם פיה עשרה אצעאף

עלי סאיר אלחכמא

ואלמנגמין

אלדי פי גמיע ממלכתה
Yefet b. 'Eli

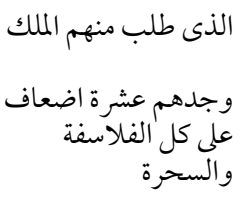

لذين فى كل ملكه

\footnotetext{
${ }^{22}$ fol. 12v , líneas 5-7.
} 
A nivel traductológico se aprecian una serie de interesantes diferencias en las estrategias adoptadas por el traductor árabe cristiano frente a las versiones de Yefet b. 'Eli y de Sa'adyah. La omisión de elementos en las versiones de Yefet b. 'Eli y en Sa'adyah las señalamos con un guión largo, en tanto que los añadidos que presentan con respecto a Sin. ar. 1 constan entre llaves $(\{\mathrm{xxx}\})$ :

Sin. ar. 1

fi kull šay'
sa'ala-hum 'an-hu
min

fiqh wa- ilm wa-

hikmah

wağada-hum fì

dalika

afdal min kull

sāḥir wa- 'arrāf

fĩ mulki-hi

bi- 'ašrah $a d ̣$ 'āf
Yefet b. 'Eli (a) /

Sa'adyah (b)

(a) wa-kull hițāb

(b) wa-kull amr

(a) $\{$ alladid $\bar{l}\}$ talaba min-hum \{al-malik\}

(b) iltamasa-hu min-hum \{almalik\}

(a) hikmah fahm

(b) wa-hikma wa-fahm

(a) wağada-hum

(b) wağada-hum fi-hi

(a) al-falāsifah wa-l-saḥrah

(b) sā'ir al-ḥikmah wa-lmunağğimīn

(a) $\{$ alladīna $\}$ fì kulli mulki-hi

(b) $\{$ allad $\bar{\imath}\}$ fi ğam $\bar{\imath}$ mamlakati-hi

(a) 'ašrat aḍ' āf 'alà kull

(b) 'ašrah aḍ̂'âf 'alà 
Desde el punto de vista de la elección del vocabulario, también ofrece Sin. ar. 1 una serie de estrategias léxicas distintas con respecto a las traducciones judeoárabes de Yefet b. 'Eli y de Sa'adyah:

\begin{tabular}{|c|c|c|}
\hline Sin. ar. 1 & $\begin{array}{c}\text { Yefet b. 'Eli (a) / } \\
\text { Sa'adyah (b) }\end{array}$ & THM \\
\hline šay’ & $\begin{array}{l}\text { (a) hițāab } \\
\text { (b) } a m r\end{array}$ & děbar \\
\hline sa'ala & $\begin{array}{l}\text { (a) țalaba } \\
\text { (b) iltamasa }\end{array}$ & $b i q \cdot q \bar{e} s$ \\
\hline Fiqh & $\begin{array}{l}\text { (a) - } \\
\text { (b) }-\end{array}$ & - \\
\hline hikmah & $\begin{array}{l}\text { (a) hikmah } \\
\text { (b) ḥikmah }\end{array}$ & $h \bar{o} \underline{\underline{k} m a \bar{a}}$ \\
\hline 'ilm & $\begin{array}{l}\text { (a) fahm } \\
\text { (b) wa-fahm }\end{array}$ & bînā \\
\hline 'arrāf & $\begin{array}{l}\text { (a) al-falāsifah } \\
\text { (b) sā'ir al-ḥukamā' }\end{array}$ & Ha-ḥarĕțm·mîm \\
\hline sāḥir & $\begin{array}{l}\text { (a) al-saḥarah } \\
\text { (b) al-muna ̌̆ğgimīn }\end{array}$ & $h \bar{a}-{ }^{\prime} a s^{\prime} \cdot \check{s} \bar{a} f i m$ \\
\hline mulk & $\begin{array}{l}\text { (a) mulk } \\
\text { (b) mamlakah }\end{array}$ & malěk $\hat{k} t$ \\
\hline
\end{tabular}

La explicación a estas diferencias léxicas responden al hecho de que la traducción contenida en Sin. ar. 1 ha sido realizada a partir de un texto siriaco. El cotejo de esta versión árabe cristiana con el texto de la Pešịttā ofrece el resultado siguiente ${ }^{23}$ :

${ }^{23}$ Sobre el texto de Daniel de la Pešịttāa, véase R.A. TAYLor, The Peshitta of Daniel (Leiden: Brill, 1994). 
Sin. ar. 1



«Y todas las cosas sobre las que les preguntó acerca de conocimiento, ciencia y sabiduría los encontró en ello diez veces superiores a cualquier mago y adivino en su reino».

\section{Pešițtā}

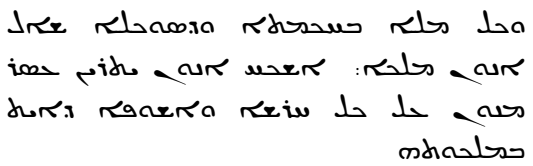

«Y en todas las cuestiones de sabiduría y conocimiento que el rey les preguntó los halló diez veces mejores que todos los magos y astrólogos que había en su reino».

Esta versión árabe cristiana presenta un texto muy cercano al de otras versiones coetáneas realizadas a partir de un original siriaco, en las que las estrategias son casi las mismas, v.gr. el ejemplo que sigue, de hacia

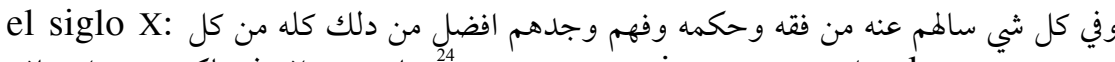
aunque no siempre es este el caso, ya que la tradición árabe cristiana ofrece otros resultados como consecuencia de estrategias distintas o debido a la Vorlage utilizada por el traductor como puede apreciarse en los dos ejemplos que siguen, en los que ambos textos han sido traducidos a partir de un original siriaco ${ }^{25}$ :

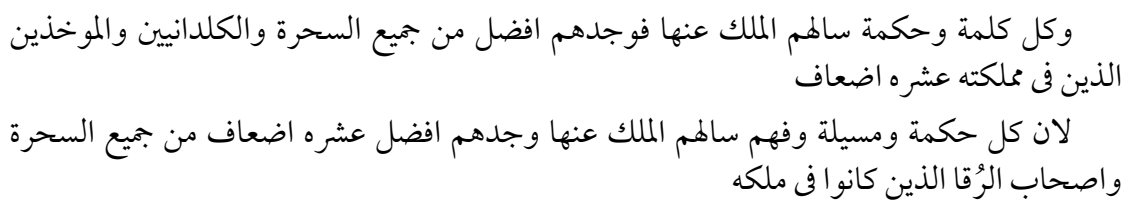

Volviendo al texto contenido en Sin. ar. 1 la correspondencia entre esta y el texto siriaco de la Pešịttā, siguiendo el orden de palabras que presenta esta segunda, es el siguiente:

${ }^{24}$ O. LöFgREN, Studien zu den arabischen Danielübersetzungen, mit besonderer Berücksichtigung der christlichen Texte (Uppsala: A.-B. Lundequistska Bokhandeln, 1936), pág. 56.

${ }^{25}$ LÖFgren, Studien $z u$ den arabischen Danielübersetzungen, págs. 61 y 65, respectivamente. 
Sin. ar. 1

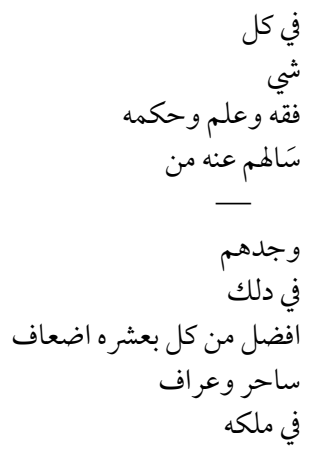

Pešițtā

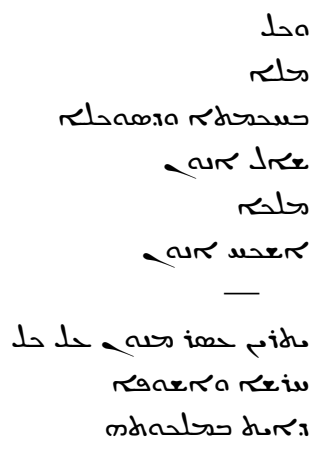

Como se aprecia, la versión transmitida por la Pešịttā ha seguido la estructura oracional de THM, que queda así:

OP

$$
\leftarrow \text { Propadj1 }
$$

$$
\leftarrow \operatorname{Padv} \leftarrow \operatorname{PAdj} 2
$$

La traducción árabe, en cambio, ha reducido la estructura oracional de acuerdo con el esquema OP $\leftarrow$ Propadv. El traductor árabe cristiano de Sin. ar. 1 se ha permitido una serie de libertades en las estrategias aplicadas a un texto traducido a partir de un original siriaco ${ }^{26}$. Dicha libertad en las estrategias, por el contrario, no es sin embargo perceptible en la elección del léxico que ha realizado el traductor árabe cristiano al verter el texto en árabe, como podemos apreciar en el listado que sigue:

- El traductor árabe ha preferido el genérico šay’ ('cosa'), que traduce el siriaco melā ('palabra, dicho, sentencia, precepto') vocablo que capta a la perfección el hebreo děbār ${ }^{27}$.

${ }^{26}$ Véanse al respecto J. P. MonFERRER-SALA, «Plumbing the depths: sidelights and strategies of the Medieval Christian Arab Translators», Journal for Semitics 19:2 (2010) págs. 661-697, e IDEM, «Estrategias de traducción en un texto árabe cristiano con Vorlage siriaca ApVir(ar) 4-5 [ApVir(sir) 5-6]», Estudios de dialectología norteafricana y andalusí 12 (2008), págs. 17-41.

${ }^{27}$ Cf. J. Blau, A Dictionary of Mediaeval Judaeo-Arabic Texts (Jerusalem: The Academy of the Hebrew Language - The Israel Academy of Sciences and Humanities, 2006), pág. 357. 
- La serie nominal trimembre figh wa-'ilm wa-hikmah ("conocimiento, ciencia y sabiduría') supone una amplificación realizada a partir de la estructura bimembre siriaca ḥekmțō $w$-děsūkalā ('sabiduría y conocimiento'), con que la Pešìttā traduce el par hebreo hộhmā bînā. Los dos términos árabes fiqh wa- ilm representan una interpretación del siriaco sūkalā ('conocimiento') desdoblando de este modo la interpretación en árabe de la voz $s \bar{u} k a l \bar{a}$, por un lado desde el punto de vista jurídico $(f i q h)^{28}$ y por otro el racional ('ilm) ${ }^{29}$.

- La forma verbal sa'ala (árabe medio [y dialectal] ${ }^{30} s \bar{a} l$ ('preguntar; interrogar') traduce su cognado siriaco šêl ('preguntar; interrogar') que reproduce el significado del hebreo biq $q \bar{e} \bar{s}^{31}$.

- El árabe wağada ('encontrar') vierte la forma siriaca anómala con 'alef prostética 'eškaḥ ('encontrar') con la que traduce la forma qal hebrea $m \bar{a} s \bar{a}^{32}$.

- La fórmula elativa árabe af̣̣al min ('mejor que...') traduce la siriaca yatīr ... 'al ('más grande que...'), sin correspondencia en THM.

- El par nominal sāhir wa-'arräf ('mago y adivino'), con valor colectivo, vierte el par siriaco ḥaraše w-'ašūfēe ('magos y astrólogos'), que son los plurales correspondientes de las hebreas harětum·mîm y 'aš‘šăfim, de donde las dos formas segundas respectivas ('ašüfē y 'ašššafim) son cognadas.

- El sintagma preposicional árabe fi mulki-hi ('en su reino; soberanía') traduce el siriaco bě-malk vierte el sintagma hebreo bě $\underline{k} \bar{o} l$-malěk $\underline{k}$ tô ('en todo su reino').

${ }^{28}$ Sobre el término fiqh, véase EI ${ }^{2}$, vol. II, págs. 906-908 (I. GoldZIHER - J. ScHACHT) у 908-912 (J. SсHАCHT).

${ }^{29}$ Acerca del término 'ilm, véase $\mathrm{EI}^{2}$, vol. III, págs. 1161-1162 (Redacción). Para 'ilm al-kalām, EI², vol. III, págs. 1170-1179 (L. GARDET).

${ }^{30}$ J. J. MARCEL, Dictionnaire français-arabe des dialectes vulgaires d'Algérie, de Tunisie, du Maroc et d'Égypte avec la prononciation figurée en lettres latines (5. ${ }^{a} \mathrm{ed}$. Paris: Maissonneuve Frères et Ch. Leclerc éditeurs 1883), pág. 331.

${ }^{31}$ Cf. Blau, A Dictionary of Mediaeval Judaeo-Arabic Texts, pág. 283.

${ }^{32}$ Cf. Blau, A Dictionary of Mediaeval Judaeo-Arabic Texts, pág. 747. 
El traductor siriaco, por lo tanto, ha adoptado dos estrategias en las que diverge con respecto al texto que presenta THM:

1. La fórmula elativa yatīr ... 'al ('más grande que...'), que no figura en THM.

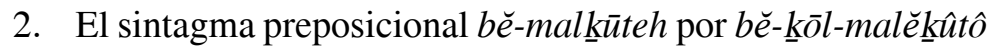
en THM.

A su vez, sin entrar en detalles de naturaleza léxica, el traductor árabe ha introducido dos cambios con respecto al texto de la Pešìttā:

1. šay' frente a melā.

2. fiqh wa- ilm wa-ḥikmah por ḥekmțō w-děsūkalā

El cotejo de estas tres traducciones de Daniel 1:20 nos indica que frente a las versiones judeoárabes, que siguen fielmente al THM, la versión que ofrece Sin. ar. 1 es más libre y su traductor se ha permitido ciertas licencias, pese a que su Vorlage siriaca también sigue al THM. Este ejemplo tan mínimo, por supuesto que no nos sirve para describir cuál era la mecánica de las traducciones judeoárabes y árabes cristianas de la Edad Media. Sin embargo, sirve para mostrar como en algunos casos, pese a haber opciones traductológicas distintas válidas, dos autores tan distintos y contrarios como Sa'adyah y Yefet b. 'Eli optan por soluciones semejantes. La explicación de porqué ambos optaron por esas soluciones al traducir el texto no es otra que la fidelidad de la versión judeoárabe con respecto al texto hebreo que tradujeron.

El taFsĩr De Yefet B. 'Eli a DANiel 1:20

El comentario que presenta Yefet b. 'Eli no es el propio de un exegeta que actúa estrictamente de acuerdo con los procedimientos hermenéuticos de los pensadores judíos influidos por el movimiento de la mu tazilah, aunque nuestro autor, como otros caraítas y rabbanitas, siguiera los pasos y las tendencias marcadas por la mu'tazilah ${ }^{33}$. Antes bien, como podre-

${ }^{33}$ Birnbaum, «Yefet b. 'Ali and His Influence on Biblical Exegesis», pág. 59. Véase, por ejemplo, el interesante caso de los tres fragmentos judeoárabes pertenecientes a obras de autores de la mu 'tazilah (entre ellos el Muhīt de 'Abd al-Ğabbār) copiados por caraítas: H. Ben-Shammai, «A Note on Some Karaite Copies of Mu'tazilite Writings», Bulletin of the School of Oriental and African Studies 37 (1974), págs. 295-304. 
mos comprobar en las líneas que siguen, nos encontramos ante un mufassir en toda regla, que no sólo desarrolla su trabajo en el ámbito estricto impuesto por los comentaria al uso ya sea al Corán o, como en este caso y otros ${ }^{34}$, al texto bíblico, sino que va incluso más allá frecuentando ámbitos propios de lo que cabría considerar como análisis sociológicos a partir de la periferia de los textos o, en otras palabras, lo que se sitúa más allá del texto, aunque en evidente relación con estos. Rasgos característicos de su técnica, entre otros reseñables, son la concisión explicativa, la sencillez expositiva, nítida y carente de todo elemento ambiguo, así como sus constantes referencias a pasajes necesarios para la correcta intelección de la secuencia o término objeto del análisis ${ }^{35}$.

El texto del comentario de Yefet b. 'Eli a Daniel 1:20 y su traducción castellana dice lo siguiente ${ }^{36}$ :

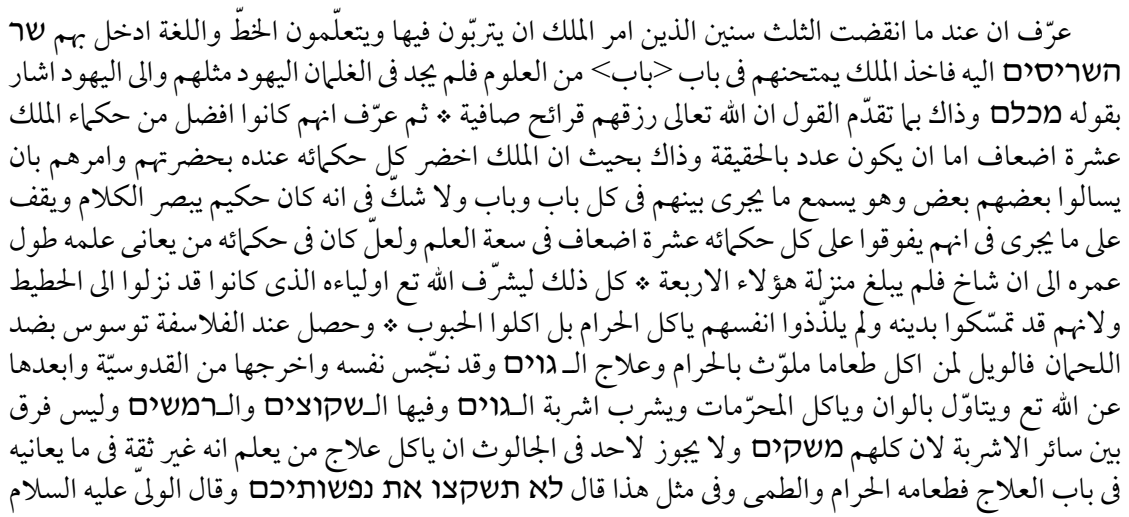

יראו את יוי קדושין : (2)

${ }^{34}$ Véase, aplicado a ejemplos sacados de las obras de Sa'adyah, J. WANsBrough, «Majāz al-Qur'ān: Periphrastic Exegesis», Bulletin of the School of Oriental and African Studies 33 (1970) págs. 247-266: 260-265.

${ }^{35}$ Birnbaum, «Yefet b. 'Ali and His Influence on Biblical Exegesis», págs. $53 \mathrm{y}$ 68-70.

${ }^{36}$ Jephet ibn Ali the Karaite, A Commentary on the Book of Daniel, págs. 12 (texto judeoárabe) y 5 (trad.). Ofrecemos la edición en caracteres árabes, tal como la presenta Margoliouth. Acerca de los 'desvíos' con respecto a las reglas del árabe clásico en el judeoárabe de Yefet b. 'Eli, véanse los ejemplos aducidos por Birnbaum, «Yefet b. 'Ali and His Influence on Biblical Exegesis», págs. 167-168. 
«Nos informó de que al concluir los tres años que el rey había ordenado para que los formasen y los instruyesen en la escritura y en la lengua, el jefe de los eunucos $\operatorname{los}_{\text {trajo }}{ }^{37}$ a su presencia y el rey empezó a examinarlos en las [diversas] categorías de las ciencias, pero no halló entre los jóvenes judíos [a nadie] como ellos (a los judíos se refiere [Daniel] con su expresión 'entre todos ellos'). Esto es por lo dicho previamente: 'Dios Altísimo les confirió unas mentes clarividentes' (Da 1:17) * Luego nos informó de que ellos eran mejores que los sabios del rey diez veces. En cuanto al número, este tanto puede ser real como figurado, ya que el rey convocó a todos sus sabios a su presencia y les ordenó que se interrogasen unos a otros, mientras él oía lo que pasaba entre ellos en cada categoría, pues no hay duda de que él era un sabio, comprendía la discusión y aprehendía cuanto acontecía, ya que ellos superaban a todos sus sabios diez veces en amplitud de conocimiento. Probablemente había entre sus sabios quien había estudiado a lo largo de su vida hasta hacerse viejo, pero sin alcanzar el nivel de estos cuatro * Todo esto era para que Dios Altísimo honrase a sus amigos, que habían sido degradados a la más baja condición, porque se habían aferrado a su religión y no se habían deleitado comiendo [alimentos] prohibidos, sino que habían comido grano * Entre los filósofos se murmuraba en contra de las carnes ‘ $¡$ Ay de quien come alimentos mezclados con lo impuro preparados por los gentiles, corrompe su alma apartándola de la santidad y alejándola de Dios Altísimo, da explicaciones varias [fuera de la Ley], come alimentos prohibidos y bebe bebidas de los gentiles que contienen [cosas] asquerosas y abominables!', sin que haya diferencia entre el resto de bebidas, porque todas ellas son líquidos. A nadie le es lícito durante el cautiverio comer lo que prepare quien se sepa que no observa la[s normas] en materia de preparación [de los alimentos] ${ }^{38}$, por lo que sus alimentos son impuros e inmundos. Semejante a esto dijo [Dios]: 'no os contaminéis' (Le 20:25), y [también] dijo lo que sigue, la paz sea con él: 'los que buscan a Adonay no echarán en falta ningún bien’ (Sal 34:10)».

${ }^{37}$ Adḩala bi-him, cf. la construcción tadāhal bi- en judeoárabe en J. BLAU, «Some additions, Mostly from Judeo-Arabic, to Dozy’s Supplément», JQR 73 (1982), págs. 112123: 121.

${ }^{38}$ Lit. 'es infiel en sus observaciones en asunto de preparación'. 
El comentario del versículo, como en otros casos, da comienzo con una paráfrasis en la que el autor relaciona el versículo con la trama narrativa que antecede, concretamente los vv. 3-19, con el objeto de situar al lector en el contexto de la narración y proveerle con todos los elementos necesarios para la intelección del texto. Esta paráfrasis es de crucial interés para el versículo en cuestión por cuanto en algunos de sus versículos, como tendremos ocasión de comprobar, ofrece Yefet b. Eli la información necesaria con la que poder comprender en toda su dimensión lo que quiere expresar en 1:20.

En esta paráfrasis Yefet b. 'Eli recurre al sintagma רָב סָרִיסָיו ('el jefe de sus eunucos') que recoge THM en Da 1:3, pero prefiriendo la lectura que ofrece Da 1:7.9.10.11.18, con lo que establece una correspondencia entre los términos rab ('señor') ${ }^{40}$ y śar ('jefe') ${ }^{41}$. Yefet b. 'Eli traduce el título רב סָרִיסִים como ra's̄s hidmah, es decir 'jefe de administración, ${ }^{42}$, que en el comentario interpreta como ağallu allad̄i kāna taḥta yadi-hi al-munğali'în min Yisrā' $\bar{l}$, esto es: 'el más importante que tenía bajo su poder a los cautivos de Israel ${ }^{43}$. La traducción es la misma en 1,7.9.10.11.18, pero ahora con artículo en el nomen rectum del status constructus ra'îs al-hidmah" ${ }^{44}$, 'el jefe de la administración' ${ }^{45}$.

A este jefe de la administración, según THM, le encargó Nabuco-

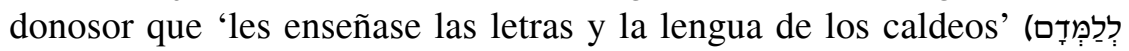

${ }^{39}$ Acerca del plural regular sārîsîm con el significado de 'eunucos', véase W. GESENIUS, Thesavrvs philologicvs criticvs lingvae hebraeae et chaldaeae Veteris Testamenti, ed. A. RoEdiger (Leipzig: W. Vogel 1835, 1840 y 1853), vol. II, pág. 973.

${ }^{40}$ Gesenius, Thesavrvs, vol. III, pág. 1.254.

${ }^{41}$ Gesenius, Thesavrvs, vol. III, pág. 1.343.

${ }^{42} \mathrm{Cf}$. la traducción errónea 'the chief of his ministers' de la construcción árabe ra'īs hidmah que ofrece Margoliouth, probablemente por contaminación con el texto bíblico, Jephet ibn Ali, A Commentary on the Book of Daniel, pág. 2 (trad.).

${ }^{43}$ Jephet ibn Ali, A Commentary on the Book of Daniel, págs. 6 (texto judeoárabe) y 2 (trad.).

${ }^{44}$ Jephet ibn Ali, A Commentary on the Book of Daniel, págs. 8, 9, 11 (texto judeoárabe) y $4-5$ (trad.).

${ }^{45} \mathrm{Cf}$. de nuevo el error de traducción que presenta Margoliouth al traducir el sintagma árabe ra'īs hidmah como 'Chief of the eunuchs' (1:18), de nuevo por contaminación con el texto bíblico; la traducción 'chief eunuch' (1:11), sin embargo procede del comentario (שר הסריסים): Jephet ibn Ali, A Commentary on the Book of Daniel, págs. 5 y 4 (trad.), respectivamente; las otras tres referencias (1:7.9.10) carecen de traducción. 


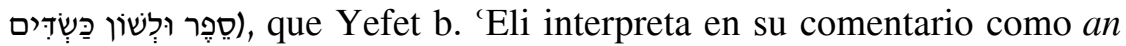
yatarabbūna fì-hā wa-yata'allamūna al-hatt wa-l-lugah ${ }^{46}$, es decir: "para que los formasen y los instruyesen en la escritura y en la lengua'. La traducción de 1:4, sin embargo ofrece: li-ta limmi-him al-hatt wa-lugat al-kasdāniyyīn, "para instruirles en la escritura y la lengua de los caldeos', que interpreta del modo siguiente: 'para que puedan escribirla y hablarla' (hattà yaktubūna bi-hā wa-yatakallamūna bi-hā), pues la desconocían $^{47}$.

En este punto tenemos que detenernos en dos elementos interesantes. En primer lugar hay que observar que el término hebreo sēfer refiere al documento escrito en sí, en tanto que en árabe la voz hatt indica la escritura, las letras, pero no el documento que contiene la escritura. Es obvio que para la traducción de sēfer, por lo tanto, hubiera resultado más apropiada la palabra kitābah ('escritura; documento [escrito]'). Y en segundo lugar, frente a la transcripción habitual entre los autores árabes cristianos ${ }^{48}$, el término kaśdîm no ha sido vertido por kaldāniyyūn (< sir. kaldayē, cf. LXX $\chi \propto \wedge \lambda \delta a i ̃ o)$, que es el resultado de un fenómeno de mutación consonántica de las sibilantes (/ś/-/š/ > /1/ ante dental /d/) que se documenta en los dialectos del medio y neoasirio (kaldu/kaldî) ${ }^{49}$, sino que Yefet b. 'Eli ha preferido mantener la lectura de la voz hebrea adaptándola a la morfología árabe como kasdāniyyūn.

No es baladí que Yefet b. 'Eli haya optado por esta traducción. De hecho, en el comentario nos indica que «ellos no conocían su escritura ni su lengua» (li'anna-hum mā kānū ya'rafūna hatța-hum wa-lā lugiata-hum) ${ }^{50}$,

\footnotetext{
${ }^{46}$ Mantengo en la transcripción del texto judeoárabe las incorrecciones propias del registro del 'árabe medio' reflejados en los textos judeoárabes. Sobre las características de este registro, véase el capítulo primero de J. BLAU, The Emergence and Lingustic Background of Judaeo-Arabic. A Study of the Origins of Middle Arabic (Jerusalem: BenZvi Institute 1981; originalmente publicado en Oxford, 1965), págs. 19-50.

${ }^{47}$ Jephet ibn Ali, A Commentary on the Book of Daniel, págs. 7 (texto judeoárabe) y 3 (trad.).

${ }^{48}$ Paul de Lagarde, Materialien zur Kritik und Geschichte des Pentateuchs (Leipzig: B. G. Treubner, 1867), vol. I, pág. 106.

${ }^{49}$ A. Lancellotti, Grammatica della lingua accadia (Jerusalem: Franciscan Printing Press, 1995), pág. $168 \S 113$ b,c,d.

${ }^{50}$ Jephet ibn Ali, A Commentary on the Book of Daniel, págs. 7 (texto judeoárabe) y 3 (trad.).
} 
de lo que se deduce algo que obviamente Yefet $b$. 'Eli conocía que la lengua que se hablaba y se escribía era una variante dialectal del arameo, frente a la lengua de los israelitas que era el hebreo ${ }^{51}$, con un sistema de escritura nacional a la vez simple y conservador. Ambos, lengua y escritura, serán cambiados con la vuelta de la clase educada que había sido exiliada a Babilonia tras la destrucción del Templo ${ }^{52}$. La traducción de Yefet b. 'Eli, por lo tanto, hay que enmarcarla en este contexto de conocimiento del autor caraíta, pues era conocedor de esa realidad histórica de la que se hace eco el Libro de Daniel y él comenta. Por otro lado, sin embargo, y paradójicamente, nada dice del valor simbólico del número tres en este contexto, cuando este número y sus múltiplos tienen un arraigado uso en la literatura hebrea y judía en general, y en la producción bíblica en particular para denotar la compleción, la totalidad de lo numerado ${ }^{53}$.

Tras este estadio inicial del comentario, Yefet b. 'Eli nos presenta, pues, el marco en el que se desenvuelve y al propio tiempo cobra razón de ser su explicación del versículo. El jefe de los eunucos -o de la administración real según la traducción árabe- trae a los jóvenes judíos mejor instruidos a presencia de Nabucodonosor, quien se percató de la inteligencia de los jóvenes judíos seleccionados al examinarlos (yamtahinu-hum) sobre cuestiones (bāb $[w a-b \bar{a} b]$ ) científicas (min al- 'ulūm). Yefet b. 'Eli nos presenta de este modo un cuadro descriptivo de la situación de acuerdo con un proceso gradativo, como podemos apreciar: hay un primer momento meramente introductorio con la sola presencia de los jóvenes judíos, que el autor interrumpe para introducir tres glosas explicativas sobre estos jóvenes judíos traídos a presencia del monarca: la primera glosa es de naturaleza meramente referencial, con el fin de explicar que el grupo de judíos era una parte tan sólo de los judíos que estaban en cautiverio babilónico, concretamente los mejores; la tercera glosa, a su vez, es utilizada por el autor para referirse a cuál pueda ser el valor (real o figurativo) de

${ }^{51}$ J. M. Fuller, An Essay on the Authenticity of the Book of Daniel (Cambridge London: Deighton, Bell \& Co. - Bell \& Daldy, 1864), pág. 92.

52 J. NAVEH, Early history of the alphabet: an introduction to West-Semitic epigraphy and palaeography (2. ${ }^{\mathrm{a}}$ ed. Jerusalem: The Magness Press - The Hebrew University, 1997), pág. 78.

${ }^{53}$ J. PHILIPS, Bible Explorer's Guide: How to Understand and Interpret the Bible (Grand Rapids, MI: Kregel Publications, 2002), pág. 137. 
la expresión «diez veces mayor» en el texto; en tanto que con la segunda glosa Yefet b. 'Eli recalca el valor que tienen los versículos previos para la comprensión del versículo que se encuentra comentando.

A esa primera escena introductoria, tras las tres glosas, sigue la segunda escena, en la que el cuadro representa ya el punto central de su explicación. En éste, el monarca convoca a «todos sus sabios» (kull hukamā'i$h i$ ), a quienes ordenó (amara-hum) que «se interrogasen unos a otros» (yas'alū ba 'ḍ -hum ba'ḍ). Las dos referencias contienen dos elementos de suma importancia: el primero es la palabra hukama'), a los que un poco antes ha calificado como hukamā' al-malik ('los sabios del rey'), con la que Yefet b. 'Eli interpreta el par nominal al-falāsifah wa-l-saharah ('los filósofos y los magos'). Pero además, en segundo lugar, tenemos el marco físico que se deduce de la segunda referencia: un grupo de «sabios» discutiendo entre ellos sobre aspectos diversos relacionados con el conocimiento ( $\mathrm{ilm}$ ), tal como se desprende del sintagma sa 'at al- ilm, 'amplitud de conocimiento', con el que se refiere a la formación tanto de los sabios del rey como de los jóvenes judíos que los superaban.

Tal cuadro no evoca otra cosa que un debate de los que tradicionalmente se atribuyen a judíos, cristianos y musulmanes en las sesiones o mağālis (sing. mağlis) ${ }^{54}$ celebrados durante la Edad Media bajo el poder árabe-islámico ${ }^{55}$. Las categorías $(b \bar{a} b w a-b \bar{a} b)$ a las que alude Yefet b. 'Eli no deben ser otras que las categorías aristotélicas ${ }^{56}$, con las que, a excepción de los lógicos como al-Fārābī e Ibn Sīnā, se daba inicio a las discusiones de naturaleza metodológica ${ }^{57}$. Es sumamente interesante, además, que en este cuadro descriptivo el monarca sea calificado por Yefet b. 'Eli como sabio (hakīm) que comprendía (yabșiru) la discusión (al-

${ }^{54}$ Daniel Frank ha llamado la atención sobre este asunto en su Search Scripture Well: Karaite Exegetes and the Origins of the Jewish Bible Commentary in the Islamic East (Leiden - Boston: Brill 2004), pág. 124 (n. 119).

${ }^{55}$ Véanse los varios trabajos incluidos en el volumen editado por H. LAZARUS-YAFFE et al. (eds.), The Majlis. Interreligious Encounters in Medieval Islam (Wiesbaden: Harassowitz, 1999).

${ }^{56}$ I. M. N. AL-Jubouri, History of Islamic philosophy with view of Greek philosophy and early history of Islam (Hertford: Bright Pen, 2004), pág. 69.

${ }^{57}$ S. Inati, «Logics», en History of Islamic Philosophy. II, eds. S. H. NASR \& O. LEAMAN (London: Routledge 1996), págs. 802-823, 804-805. 
kalām) aprehendiendo cuanta información circulaba en las discusiones. Vuelve a tener especial relevancia en este contexto el término $\mathrm{kalăm}^{58}$, que es un recurso habitual entre los teólogos especulativos musulmanes, y también entre los judíos, tanto rabbanitas como caraítas, como da fe de ello al-Qirqisānī en el libro IV de su Kitāb al-anwār o 'Libro de las luminarias' de acuerdo con la información que nos ha llegado de esta obra perdida $^{59}$.

Tampoco tiene desperdicio la alusión de corte generacional que hace Yefet b. 'Eli al referirse a la formación de los jóvenes, que superaban en conocimiento a los sabios después de que estos hubieran estudiado durante toda su vida hasta alcanzar la ancianidad (man yu'ān $\bar{\imath}$ 'ilma-hu țūl 'umri-hi ilà an šăh fa-lam yablag manzilata hä'ulä' alarbi 'ah). Creemos que se trata de una alusión al poder establecido de los sabios del judaísmo oficial, concretamente de una referencia a Sa'adyah y a sus seguidores, pues en el momento en el que la formula Yefet b. 'Eli, el gaón Sa'adyah era ya una reputada figura y mucho más mayor que él ${ }^{60}$. A juzgar por esta alusión, para Yefet b. 'Eli el enfrentamiento entre rabbanitas y caraítas no sólo representa una oposición en las creencias y en los planteamientos ante los textos, sino también de una confrontación generacional entre un saber oficializado cuya interpretación de los textos bíblicos se mueve en función de sus intereses concretos y otra, la caraíta, fundamentada en el valor intrínseco y exclusivo de los textos.

A esta alusión generacional la envuelve rápidamente Yefet b. 'Eli con la justificación de la narración de los hechos expuestos por el texto daniélico mediante una justificación exegética fundada concretamente sobre 1:8-12.17. Los alimentos prohibidos a los que alude Yefet b. 'Eli, calificados como al-harām, es «la comida del rey» (paț-bag ha-melek «y el vino que bebía» (ûmiyyên mištāyyw) y aunque no especifica el tipo exacto de alimentos de que se trata se infiere que estos no se atenían a

\footnotetext{
${ }^{58}$ Véase al respect H. A. WoLfSON, «The Jewish Kalām», JQR 57 (1967), págs. 544573.

${ }^{59}$ B. ChIESA, «A note on Early Karaite History», History and Theory 27:4 (1988), págs. 56-65: 61-62.

${ }^{60}$ M. G. WeChSLER, The Arabic Translation and Commentary of Yefet ben 'Eli the Karaite on the Book of Esther (Leiden: Brill, 2008), pág. 4 (n. 8).
} 
las prescripciones que ordena la Ley. La palabra pat-bāg es un préstamo persa, deformación del persa antiguo *patibāga ('porción') ${ }^{61}$. Por otro lado, «los granos/semillas» $(a l-h ̣ u b \bar{u} b)$ que señala como comida de los jóvenes judíos es la interpretación que hace Yefet b. 'Eli del plural regular hebreo ha-zēēồ $(1: 12)$ o zēr' 'onîm (1:16). La explicación de que Yefet b. 'Eli no haya recurrido al cognado árabe $z u r \bar{u}$ ' ('semillas; simientes') ${ }^{62}$ se explica porque el significado del término hebreo se ha especializado en el significado 'legumbres', preferiblemente, aunque no en exclusiva, del género de las leguminosas, tal como sucede con el significado del plural irregular árabe ḥubūb (sing. ḥabb) ${ }^{63}$, de donde la elección del término, como podemos comprender a tenor de lo que indicamos más abajo.

La secuencia final la dedica Yefet b. 'Eli a los alimentos y a las bebidas, así como a las mezclas en ambos derivadas de la preparación realizada por los gentiles (al-gôyim). Esta referencia a alimentos y bebidas no es gratuita, por cuanto no sólo representa una importante seña de identidad simbólica, incluso en nuestros días, en el deber de preservar la cultura de las comunidades de caraítas ${ }^{64}$, sino que además refleja la fuerte oposición existente en materia de consumo de alimentos y bebidas entre los rabbanitas y los caraítas en la Palestina de esos momentos ${ }^{65}$, que les llevaba, incluso, a rechazar alimentos procedentes de los gentiles salvo verduras, legumbres o frutas ${ }^{66}$.

${ }^{61}$ Cf. Gesenius, Thesavrvs, vol. II, pág. 1137. Véase M. Ellenbogen, Foreign words in the Old Testament, their origin and etymology (London: Luzac \& Company, Ltd., 1962), pág. 141. Sobre los persismos en el Libro de Daniel, véase FulLer, An Essay, págs. 88-94.

${ }^{62}$ Gesenius, Thesavrvs, vol. I, págs. 433-434.

${ }^{63}$ G. W. Freytag, Lexicon arabico-latinum (Halle: C. A. Schwetschke et filium 1830), vol. I, págs. 330-331.

${ }^{64}$ R. Tsoffar, The Stains of Culture. An Ethno-Reading of Karaite Jewish Women (Detroit, MI: Wayne State University Press, 2006), pág. 136. Cf. J. Olszowy-Schlanger, Karaite Marriage Documents from the Cairo Geniza: Legal Tradition \& Community Life in Medieval Egypt \& Palestine (Leiden - New York - Köln: Brill, 1997), pág. 250.

${ }^{65}$ M. GIL, A History of Palestine, 634-1099. English Translation by E. Broido (Cambridge: Cambridge University Press, 1992), pág. 811.

${ }^{66}$ W. H. RuLE, «The Karaite Jews», The London Quarterly Review 35 (1870), págs. 145-161: 155 . 
Lo interesante de la secuencia, además de las referencias que ofrece el autor, es que esas murmuraciones contra las carnes (hașala [...] tawaswasu bi-ḍidd al-laḥmānn) son puestas en boca de los filósofos, al-falāsifah. A este propósito, tenemos noticia de que Sa'adyah escribió en su Tafsìr al Libro de Daniel contra la prohibición de consumir carne en la Diáspora ${ }^{67}$, muy probablemente refiriéndose a 'Anān, cuya prescripción fue seguida por muchas de las autoridades caraítas ${ }^{68}$. Sabemos que Sa'adyah siguió la vía del kalām y le fueron familiares las ideas aristotélicas, de donde muchos de los argumentos utilizados en sus comentaria biblica son el resultado de la fusión de las ideas aprehendidas de los mutakallimūn musulmanes de la $m$ ' $^{\prime}$ tazilah $^{69}$, así como de los argumentos aristotélicos transmitidos por los pensadores árabes, aunque no siempre coincidiera este con las deducciones de aquellos. Es más, a la luz de los datos con que contamos, Sa'adyah fue el fundador de la tradición filosófica en la que las Sagradas Escrituras comenzaron a ser interpretadas desde una óptica judía rabínica ${ }^{70}$.

Lo anteriormente expuesto nos lleva a considerar que con la denominación al-falāsifah Yefet b. 'Eli se estaba refiriendo a Sa'adyah y a sus seguidores ${ }^{71}$. El plural falāsifah traduce en Yefet b. 'Eli al hebreo haraẹtum·mîm, cuyo significado, que oscila en términos generales entre los valores de 'adivinos, astrólogos y magos', se enmarca en una amplio marco en el que se incluían tanto a nigromantes, como a prestidigitadores y a astrólogos. El traductor árabe cristiano de Sin. ar. 1, por ejemplo, interpretó sāḥir como 'mago' al traducir el plural siriaco haraše e ('magos'). Esta interpretación negativa coincide con la actitud negativa que tenían la mayoría de los pensadores judíos duran-

${ }^{67}$ Jephet ibn Ali, A Commentary on the Book of Daniel, pág. vii.

${ }^{68}$ S. PozNAŃskI, «The Anti-Karaite Writings of Saadiah Gaon», JQR [OS] 10 (1898), págs. 238-276: 243-244 (n. 6).

${ }^{69}$ D. Freidenreich, «The Use of Islamic Sources in Saadia Gaon's Tafsìr of the Torah», JQR 93 (2003), págs. 353-395.

${ }^{70}$ E. SchweID, The Classic Jewish Philosophers: From Saadia through the Renaissance. III, trad. L. Levin (Leiden - New York - Köln: Brill 2007), págs. 3-38.

${ }^{71}$ H. HirschFeld, Jefeth b. Ali's Arabic Commentary on Nāhūm. With Introduction, abridged Translation and Notes (London: Jews' College Publications, 1911), pág. 6. Véase también Jephet ibn Ali, A Commentary on the Book of Daniel, pág. 152. 
te la Edad Media con respecto a la astrología ${ }^{72}$. No es paradójico, sin embargo, que Sa'adyah haya traducido ḥarẹtum·mîm como sä'ir alhukamā', esto es 'el resto de los sabios', confiriendo de este modo al término una interpretación positiva, pues en realidad $\mathrm{Sa}$ 'adyah mantuvo una actitud ecléctica hacia los astrólogos y sus prácticas y por ende hacia la astrología por la bondades que ésta pudiera aportar en el escrutado de los textos bíblicos ${ }^{73}$.

Por otro lado, el odio, por ejemplo, entre la poesía y la filosofía -y en algunos casos entre los poetas teólogos y los filósofos- es un conocido tema de la Antigüedad en la que Platón, Aristóteles y también las ideas atribuidas a Sócrates desempeñaron un interesante papel tanto literario, como sociológico y ético para la formación de los individuos ${ }^{74}$. Además, el odio a los filósofos no es un hecho aislado entre los autores caraítas y menos aún si este racionalismo va acompañado de creencias basadas en la magia astral, como acontece con los racionalistas judíos bizantinos de los días de Aarón b. Elías (m. 1369), autor de una serie de polémicas contra los filósofos, que en modo alguno representaban un ataque a quienes profesaban posicionamientos aristotélicos, sino contra pensadores imbuidos de un recio racionalismo al modo del que profesaban los pensadores gentiles, revestido con creencias procedentes de la magia astral ${ }^{75}$.

También la actitud de Yefet b. 'Eli es bien clara a este respecto, porque el caraíta tenía a la astrología por una técnica adivinatoria o presti-

${ }^{72}$ R. BARKAI, «L'astrologie juive médiévale; aspects théoriques et pratiques», $L e$ Moyen Age 93 (1987), págs. 323-348.

${ }^{73} \mathrm{H}$. Ben-ShammaI, «Saadia's Introduction to Daniel: Prophetic Calculation of the End of Days vs. Astrological and Magical Speculation», Aleph 4 (2004), págs. 11-87: 1145 (estudio), 46-87 (texto y traducción). Véase también B. R. GoldSTEIN, «Astronomy and the Jewish Community in Early Islam», Aleph 1 (2001), págs. 17-57: 39-42.

${ }^{74}$ Véase, aplicado a Sócrates, Platón y Aristóteles, R. BARfIELD, The Ancient Quarrel between Philosophy and Poetry (Cambridge: Cambridge University Press, 2011), págs. 10-51 (cf. además págs. 142 y 193).

${ }^{75}$ D. J. LASKER, «Aaron ben Joseph and the Transformation of Karaite Thought», en Torah and Wisdom: Studies in Jewish Philosophy, Kabbalah, and Halakha. Essays in Honor of Arthur Hyman, ed. R. Link-SALINGER (New York: Shengold, 1992), págs. 121-128; véase, además, D. Schwartz, «Conceptions of Astral Magic within Jewish Rationalism in the Byzantine Empire», Aleph 3 (2003), págs. 165-211. 
digitadora $^{76}$. Es obvio, por consiguiente, que la actitud de éste hacia los falāsifah no era ni mucho menos positiva ${ }^{77}$. En este sentido, el marco que nos ofrece Yefet $\mathrm{b}$. 'Eli es el de un mağlis presidido por Nabucodonosor, que en realidad actúa como trasunto del califa del momento que, de acuerdo con el género literario polemista, era la autoridad (o su correspondiente sustituto: un visir, un general, etc.) que acostumbraba a presidir los debates en los que intervenían los polemistas participantes. En el mağlis visualizado por Yefet b. 'Eli en su Tafsīr a este texto de Daniel los participantes incluyen a la ya mencionada autoridad y a dos grupos de litigantes en torno al saber: los sabios al servicio de esa autoridad (i.e. filósofos y magos) y a los jóvenes judíos, que son superiores a aquéllos.

\section{CONCLUSIÓN}

No nos encontramos ante una ocasión aislada en la que Yefet b. 'Eli se refiere a hechos, circunstancias o acontecimientos acaecidos en los días que le cupo vivir ${ }^{78}$. En este caso concreto se trata de un cuadro tripartito utilizado para figurar, lógicamente, una escena intencionadamente creada por el autor del comentario. De acuerdo con esta figuración, la autoridad (Nabucodonosor $=$ califa de cada momento) representa a la oficialidad establecida, el poder, de quien dependen los intelectuales afectos a ese poder, a quien sirven tanto ellos como su ciencia en detrimento de la verdad revelada por Dios a su pueblo. Enfrente de ambos grupos se encuentra un tercer grupo, el de aquellos que son superiores -tanto en saber, como en integridad- a ese poder establecido al que se han vendido sus partidarios. Este tercer grupo, representado en el cuadro daniélico por los jóvenes judíos, se corresponde en la realidad visualizada por Yefet b. 'Eli con la élite intelectual formada por los autores caraítas.

Se trata, por lo tanto, de un sutil cri de coeur que entona Yefet b. 'Eli contra la realidad socio-religiosa de sus días ${ }^{79}$, aun cuando la división

${ }^{76}$ G. VAJDA, Deux commentaires Karaïtes sur l'Ecclésiaste (Leiden. E. J. Brill 1971), pág. 131 (n. 2).

${ }^{77}$ Frank, Search Scripture Well, pág. 124 (n. 119).

${ }^{78}$ H. Ben-ShammaI, «The Attitude of the Early Karaites Towards Islam», en Studies in Medieval Jewish History and Literature, ed. I. TwersKy (Cambridge, Mass.: Harvard University Press, 1984), vol. II, págs. 1-40: 16-19.

${ }^{79}$ Lamentablemente nos ha sido imposible consultar la tesis doctoral ya mencionada 
entre rabbanitas y caraítas no sea tan acusada por el simple hecho de que el movimiento caraíta no contaba, de facto, con una fuerza opositora totalmente efectiva más allá de sus círculos. Así, mientras que la Verdad y la Ley están de parte de los caraítas, sin embargo, poder y saber están controlados por la oficialidad de la mayoría rabbanita a la que Yefet $b$. 'Eli consagró no pocos de sus esfuerzos polemistas ${ }^{80}$. Y si pensamos que filosofía y ciencia actuaban como soporte de los principios del judaísmo, entonces resulta evidente que el estudio y el ejercicio de ambas se convertía consecuentemente en una obligación filosófica que todo intelectual estaba obligado a cumplir de forma íntegra.

De este modo, Yefet b. 'Eli se ha servido del recurso literario de la trasposición con el que ha adaptado la escena del texto real que comenta a la realidad de los días que le cupo vivir al autor caraíta. De forma tan sutil como inteligente, Yefet b. 'Eli interpreta el texto y al mismo tiempo nos regala una vívida imagen de cuál era la realidad intelectual del momento, aunque -así lo pensamos- con un valor proléptico, donde los campeones de la fe y del saber, los caraítas, acabarían imponiendo su verdad sobre ese poder entregado a unos intereses propios alejados de la Ley y de la Verdad.

Recibido: $23 / 09 / 2011$

Aceptado: 16/11/2011

más arriba de Haggai Ben-Shammai, The Doctrines of Religious Thought of Abū Yūsuf Ya'qūb al-Qirqisānī and Yefet Ben 'Elī.

${ }^{80}$ Polliack, The Karaite Tradition of Arabic Bible Translation, pág. 17. 